\title{
Transformation of hydroquinone to benzoquinone mediated by reduced graphene oxide in aqueous solution
}

\author{
Chunmei Li ${ }^{a}$, Lingyun $\mathrm{Li}^{b}$, Lixiang Sun ${ }^{c}$, Zhiguo Pei ${ }^{a, *}$, Jieli Xie ${ }^{a}$, Shuzhen Zhang ${ }^{a}$ \\ a State Key Laboratory of Environmental Chemistry and Ecotoxicology, Research Center for Eco-Environmental Sciences, Chinese Academy \\ of Sciences, PO Box 2871, Beijing 100085, China \\ b Supervision and Testing Center for Vegetable Quality, Ministry of Agriculture, The Institute of Vegetables and Flowers, Chinese Academy of \\ Agricultural Sciences, Beijing 100081, China \\ c College of Chemistry and Materials Science, Ludong University, Yantai 264025, China
}

\section{A R T I C L E I N F O}

Article history:

Received 9 November 2014

Accepted 9 March 2015

Available online 14 March 2015

\begin{abstract}
A B S T R A C T
The mediation effect of reduced graphene oxide ( $\mathrm{rGO}$ ) on the oxidative transformation of 1,4-hydroquinone $\left(\mathrm{H}_{2} \mathrm{Q}\right)$ to 1,4-benzoquinone $(\mathrm{BQ})$ in aqueous solution was investigated using a batch method and electron paramagnetic resonance. The results showed that the autoxidation of $\mathrm{H}_{2} \mathrm{Q}$ was spin-restricted and extremely slow in acidic and neutral $\mathrm{pH}$ range, but this process can be dramatically accelerated when rGO was added. In the presence of $33.3 \mathrm{mg} \mathrm{L}^{-1} \mathrm{rGO}$, more than $76.0 \%$ of $\mathrm{H}_{2} \mathrm{Q}$ was oxidized to $\mathrm{BQ}$ within $36 \mathrm{~h}$. The enhancement effects of rGO were attributed to the combined contribution of the high chemical reactivity of graphenic edges and defects on rGO and the high electron conductivity of graphene basal surface of rGO. It is proposed that dissolved oxygen reacted with graphenic edges and defects of rGO to produce surface-bound oxygen intermediates, which capture $\mathrm{H}$ atoms from the phenolic hydroxyl groups of $\mathrm{H}_{2} \mathrm{Q}$ and facilitate the generation of semiquinone radical $\left(\mathrm{SQ}^{-}\right)$. The generated $\mathrm{SQ}^{-}$continued to transfer an electron to molecular oxygen to yield superoxide radical $\left(\mathrm{O}_{2}^{-}\right)$and $\mathrm{BQ}$. As a chain-carrying radical, $\mathrm{O}_{2}^{-}$further reacted with $\mathrm{H}_{2} \mathrm{Q}$ to produce $\mathrm{SQ}^{--}$and $\mathrm{H}_{2} \mathrm{O}_{2}$.
\end{abstract}

(c) 2015 Elsevier Ltd. All rights reserved.

\section{Introduction}

Graphene is a two-dimensional structure consisting of $\mathrm{sp}^{2}$ hybridized carbons that is only one atom thick, and can be regarded as the basic building block of other $\mathrm{sp}^{2}$ hybridized carbon materials, such as graphite, fullerene, carbon nanotubes, etc [1]. Since its discovery, graphene-based nanomaterials (GBNs) have been demonstrated to have promising applications in diverse disciplines [2]. In environment science and technology, GBNs are mainly considered as superior adsorbents to remove contaminants from waters and gases due to its large theoretical specific surface area and high ability of modification [3-9]. For example, it was found that sulfonated graphene was one of the best adsorbents for 1 -naphthol due to the occurrence of $\pi-\pi$ interaction between 1-naphthol and graphene surface [4]. Sun et al. [7] showed that the maximum adsorption capacity of acridine orange on graphene oxide (GO) reached striking $3.3 \mathrm{~g} \mathrm{~g}^{-1}$. In addition,

\footnotetext{
* Corresponding author.

E-mail address: peizg@rcees.ac.cn (Z. Pei). 
it is showed that GBNs had high adsorption capacity for other contaminants, such as heavy metals [10,11], antibiotics [8], pesticides [9], polycyclic aromatic hydrocarbons and their derivatives [6].

However, it should be noted that most of previous studies were usually conducted on the modification of pristine graphene, and on the adsorption ability examination of these GBNs. Few people recognized the fact that GBNs can accelerate the transformation or degradation of some organic contaminants in the adsorption process. For example, previous research suggested that 1,4-hydroquinone $\left(\mathrm{H}_{2} \mathrm{Q}\right)$ had much higher adsorption capacity than phenol because the additional $-\mathrm{OH}$ groups on $\mathrm{H}_{2} \mathrm{Q}$ facilitated the formation of $\pi-\pi$ interaction and enhanced its adsorption on reduced graphene oxide (rGO) [12]. In the present study we find a different phenomenon, where most of $\mathrm{H}_{2} \mathrm{Q}$ is transformed to 1,4benzoquinone $(B Q)$ in the presence of rGO instead of the strong adsorption on rGO surface. Fu et al. $[13,14]$ showed that rGO significantly facilitated the reduction of nitrobenzene and hexachloroethane by $\mathrm{Na}_{2} \mathrm{~S}$ in aqueous solutions. Sun et al. [15] found that rGO was able to effectively activate peroxymonosulfate to produce active sulfate radicals, and then accelerated the decomposition of phenol, chlorophenols and dyes. It is well known that the graphitic surfaces of rGO have extraordinarily high electron conductivity, and thus may facilitate the redox reactions by enhancing electron transfer [16,17]. In addition, dissolved oxygen can react with the active sites (defects, heteroatom, or metal impurities) on carbon nanomaterials to form reactive oxygen species [18-21], which have high oxidation activity for coexisting reductants [18]. Therefore, studies on the mediation effects of GBNs on the redox reactions of organic contaminants are necessary due to their inevitable release into the environment. Relative knowledge is very important for the risk assessment of both GBNs and organic contaminants in the environment [22].

In this work, we study the oxidation reaction of $\mathrm{H}_{2} \mathrm{Q}$ mediated by rGO under ambient aerobic aqueous environment. Different factors such as rGO dosage, $\mathrm{pH}$, different mediators and dissolved oxygen are examined. $\mathrm{H}_{2} \mathrm{Q}$ is a major environmental pollutant from various industrial processes, such as coke, pesticides and dyes. Exposure to $\mathrm{H}_{2} \mathrm{Q}$ residue can cause a variety of adverse consequences, including acute and chronic toxicity. The objectives of this study are (i) to investigate the potential role of rGO in accelerating the oxidation of $\mathrm{H}_{2} \mathrm{Q}$; (ii) to examine the impact of reaction conditions; and (iii) to provide an insight into the involved reaction mechanisms.

\section{Experimental}

\subsection{Materials}

$\mathrm{H}_{2} \mathrm{Q}$ (98.0\%) and BQ (99.0\%) were purchased from Aldrich Chemical Co. Inc. (Milwaukee, WI), and used as-received. $\mathrm{HCl}, \mathrm{NaOH}, 3-(\mathrm{N}-\mathrm{Morpholino})$ propanesulfonic acid sodium salt (MOPS), and other reagents are analytical grade. Methanol is of HPLC grade. GO was prepared by a modified Hummers method [23] from pure graphite (99.9\%, Nanjing XFNANO Materials Tech., Jiangsu, China), and rGO was obtained by thermal exfoliation/reduction using graphite oxide as a precursor [24]. Detailed process has been provided in the "Supplementary data".

\subsection{Characterization of $r G O$}

rGO was characterized by transmission electron microscopy (TEM), scanning electron microscopy (SEM), X-ray photoelectron spectroscopy (XPS), X-ray diffraction (XRD), and Raman spectroscopy. TEM image was collected with an H-7500 (Hitachi, Japan). SEM image was obtained on a field emission scanning electron microscope (SU-8020). The surface functional groups of rGO were determined by XPS (Perkin-Elmer PHI 550 ESCA/SAM, U.S.). The crystallographic structures of rGO and graphite were determined by XRD patterns on an $\mathrm{X}$ ' Pert PRO diffractometer (PANalytical, Holland) with $\mathrm{Cu} \mathrm{K} \alpha$ radiations generated at $40 \mathrm{kV}, 40 \mathrm{~mA}$. Scattering angles were ranged from $5^{\circ}$ to $40^{\circ}$ with a scanning speed at $1^{\circ}$ per minute. Raman spectra were recorded with a Renishewin via Raman spectrometer (Renishawplc, UK). The elemental compositions (C, H, O) of rGO were determined with a high-temperature combustion method (PE 2400 SERIES II analyzer, PekinElmer, Inc., USA).

\subsection{Batch reaction experiments}

The reaction kinetic experiment was carried out by mixing $1.0 \mathrm{mg}$ rGO with $30 \mathrm{~mL}$ Milli-Q water $\left(33.3 \mathrm{mg} \mathrm{L}^{-1}\right)$ containing $100 \mu \mathrm{M} \mathrm{H} \mathrm{H}_{2} \mathrm{Q}$ in $50 \mathrm{~mL}$ glass flasks. All the solutions were prepared fresh daily. MOPS (2.0 mM) was used to control the solution $\mathrm{pH}$ at 6.7 because it was found to have negligible effect on the oxidation reactions of $\mathrm{H}_{2} \mathrm{Q}$. Under such conditions, $\mathrm{H}_{2} \mathrm{Q}$ was present in solution as neutral form. The suspension was shaken in dark at $130 \mathrm{rpm}$ at $25 \pm 1^{\circ} \mathrm{C}$. At different time intervals, the suspension was filtered through $0.22 \mu \mathrm{m}$ membrane to separate liquid and solid phases, and the concentrations of $\mathrm{H}_{2} \mathrm{Q}$ and $\mathrm{BQ}$ in the filtrate were determined immediately by HPLC (Agilent 1200). Considering the possible adsorption of $\mathrm{H}_{2} \mathrm{Q}$ and $\mathrm{BQ}$ on $\mathrm{rGO}$, the collected rGO were freeze-dried and eluted with $5.0 \mathrm{~mL}$ methanol for twice. The final concentrations of $\mathrm{H}_{2} \mathrm{Q}$ and $\mathrm{BQ}$ were the sum of those in the filtrate and on rGO. Control was also prepared identically but contained no rGO, which was simultaneously run to assess the loss and the stability of $\mathrm{H}_{2} \mathrm{Q}$. Results show that no significant loss of $\mathrm{H}_{2} \mathrm{Q}$ was observed, indicating that microbial degradation, volatilization, or adsorption to the glass walls were negligible during the reaction process.

Separate sets of experiments were carried out to examine the effects of rGO dosages, solution $\mathrm{pH}$, carbonaceous materials and dissolved oxygen on the oxidation reaction of $\mathrm{H}_{2} \mathrm{Q}$. In the rGO dosage experiment, a total of seven rGO dosages, from 0 to $50 \mathrm{mg} \mathrm{L}^{-1}$, were investigated. In the $\mathrm{pH}$ experiments, solution $\mathrm{pH}$ was adjusted from 3.0 to 10.0 by addition of $0.1 \mathrm{M}$ $\mathrm{HCl}$ or $\mathrm{NaOH}$. Initial concentrations of both $\mathrm{H}_{2} \mathrm{Q}$ and $\mathrm{rGO}$ were $100 \mu \mathrm{M}$ and $33.3 \mathrm{mg} \mathrm{L}^{-1}$, respectively. In order to investigate the structural effects of mediators on the $\mathrm{H}_{2} \mathrm{Q}$ oxidation reaction, different carbonaceous materials (rGO, GO and graphite) were chosen. In the dissolved oxygen experiments, the reaction was initiated through mixing $1.0 \mathrm{mg}$ rGO with $30 \mathrm{~mL}$ Milli-Q water $\left(33.3 \mathrm{mg} \mathrm{L}^{-1}\right.$ ) containing $100 \mu \mathrm{M} \mathrm{H}_{2} \mathrm{Q}$ in glass 
flasks. The Milli-Q water was prepurged with $\mathrm{N}_{2}$ to remove dissolved oxygen. At different time intervals, the suspension was filtered through $0.22 \mu \mathrm{m}$ membrane to separate liquid and solid phases for HPLC determination. In comparison, a same reaction was performed using water containing dissolved oxygen. All reaction data were collected in triplicate, and the incubated time of all reactions was $36 \mathrm{~h}$ except $\mathrm{pH}$ experiment $(12 \mathrm{~h})$.

\subsection{Analysis}

$\mathrm{H}_{2} \mathrm{Q}$ and $\mathrm{BQ}$ were determined by an Agilent 1200 reversedphase HPLC (Atlantis-dC18 ODS HPLC column, 4.6 i.d. $\times 150 \mathrm{~mm}, 5 \mu \mathrm{m}$ ) equipped with UV detector. The determination wavelengths were set at $290 \mathrm{~nm}$ for $\mathrm{H}_{2} \mathrm{Q}$ and $246 \mathrm{~nm}$ for $\mathrm{BQ}$ respectively. The mobile phases were methanol:water (10:90, v:v, pH 3.0, adjusted with acetic acid) at a flow rate of $1.0 \mathrm{~mL} \mathrm{~min}^{-1}$. Chromatograms and UV spectra of $\mathrm{H}_{2} \mathrm{Q}$ standard, $\mathrm{BQ}$ standard and the oxidized product in the HPLC analysis are shown in Fig. S1. Both the retention time and UV spectra verify that the oxidized product of $\mathrm{H}_{2} \mathrm{Q}$ is $B Q$. The concentrations of $\mathrm{H}_{2} \mathrm{Q}$ and $\mathrm{BQ}$ were measured according to calibration curves prepared by corresponding standard compounds. All calibration curves included at least six concentration levels over the test concentration range with linear correlation coefficients $\left(R^{2}\right)$ of at least $0.999 . \mathrm{H}_{2} \mathrm{O}_{2}$ was measured using the Amplex Red method [25].

\subsection{Electron paramagnetic resonance (EPR) spectroscopy}

Samples for EPR analyses were prepared in the same manner as that described in the batch reaction experiment except the initial solution concentration $\mathrm{H}_{2} \mathrm{Q}$ was $10.0 \mathrm{mM}$. After reaction, the suspended solutions were used immediately for EPR measurement without filtration.

EPR spectroscopy was done using an EMX Plus EPR spectrometer (Bruker, USA) equipped with a high-sensitivity cavity and an Aqua-X sample holder. Spectra were obtained at room temperature. Typical EPR parameters were as follows: 3500 G center field; 80 G sweep width; $9.85 \mathrm{GHz}$ microwave frequency; $10.0 \mathrm{~mW}$ power; $30 \mathrm{~dB}$ receiver gain; modulation frequency of $100 \mathrm{kHz}$; modulation amplitude of $1.0 \mathrm{G}$; with the time constant being $164 \mathrm{~ms}$ with one X-scan for each 1024 point spectrum.

\subsection{Data analysis}

All data were analyzed using Origin 8.0. One-way analysis of variance was used to assess the significant difference between groups at $p<0.05$ level of significance.

\section{Results and discussion}

\subsection{Characterization of $r G O$}

Selected physical and chemical properties of rGO are given in Table S1. The BET specific surface area of rGO is found to be $300 \mathrm{~m}^{2} \mathrm{~g}^{-1}$. Elemental analysis result suggests that the prepared rGO includes about $86.59 \%$ carbon content and $10.51 \%$ oxygen content. The results of TEM and SEM of the prepared rGO are shown in Fig. S2. It was found that rGO is closely agglomerated together in the form of thin and randomly aggregated nanosheets (Fig. S2a), and has typically wrinkled, sheet-like structure (Fig. S2b). Using the scaling law: layer number $=2600 / A_{B E T}$, we estimated the average layer number of rGO is $\sim 8$ layers, belonging to multilayer graphene [26].

Fig. 1a shows the XRD patterns of graphite and rGO. The very intense and narrow peak at $26.5^{\circ}$ corresponds to the graphite spacing (002) of graphite plane. After exfoliation, it is found that the peak of graphite (002) broadens and the intensity of this peak decreases significantly, suggesting the appearance of the distorted graphite structure. This is also an indication that the prepared sample comprises largely free graphene sheets.

Fig. 1b shows Raman spectra of graphite and rGO, which are used to monitor the structural changes during the preparation of rGO from graphite. Raman spectrum of graphite displays two prominent peaks at 1328 and $1574 \mathrm{~cm}^{-1}$, which correspond to the documented $\mathrm{D}$ band and $\mathrm{G}$ band, respectively. It is well known that the $\mathrm{G}$ band corresponds to the in-plane vibrations of the graphitic structure, and the D band is related to structural defects, amorphous carbon, or edges that can break symmetry and selection rule. When graphite is exfoliated to rGO, it is found that the D band and G band broaden and the intensity of D band increases. Defect content is given by the ratio of $D$ band to $G$ band intensity (ID/IG). Compared with graphite, the ID/IG of rGO increases from 0.29 to 0.87 , indicating the increase of amorphous carbon and structural defects.

XPS provides useful information on the nature of functional groups and on the defects on rGO. In Fig. 1c, the C 1s XPS spectrum of rGO can be deconvoluted into four components. The dominant peak of $\mathrm{sp}^{2} \mathrm{C}=\mathrm{C}$ at $284.6 \mathrm{eV}$ is attributed to the graphitic structure. Several small peaks of $\mathrm{C}-\mathrm{O}$ at $286.0 \mathrm{eV}, \mathrm{C}=\mathrm{O}$ at $288.2 \mathrm{eV}$, and $\mathrm{O}-\mathrm{C}=\mathrm{O}$ at $290.0 \mathrm{eV}$ are assigned to carbon atoms attached to different oxygen-containing moieties.

\subsection{Reaction kinetics of $\mathrm{H}_{2} \mathrm{Q}$ mediated by $r \mathrm{GO}$}

The oxidation reaction of $\mathrm{H}_{2} \mathrm{Q}$ in aqueous solution mediated by rGO is presented in Fig. 2. All reaction kinetics data fitted the pseudo-first-order kinetic model well (Eq. (1)), suggesting that the oxidation reaction is first-order with respect to the concentrations of $\mathrm{H}_{2} \mathrm{Q}$.

$\mathrm{C}_{\mathrm{t}}=\mathrm{C}_{0} \times \mathrm{e}^{-k_{\mathrm{obs}} \mathrm{t}}$

where $k_{\text {obs }}$ is the pseudo-first order rate constant, $C_{t}$ and $C_{0}$ are the concentrations of $\mathrm{H}_{2} \mathrm{Q}$ at a given time $t$ and time zero, respectively. The corresponding fitting parameters are listed in Table 1. In the absence of $\mathrm{rGO}$, it is found that $\mathrm{H}_{2} \mathrm{Q}$ is rather stable at the examined time range and no significant reaction occurs. When rGO is added to the reaction system, more than $76.0 \%$ of $\mathrm{H}_{2} \mathrm{Q}$ is oxidized within $36 \mathrm{~h}$, suggesting the mediation effect of $\mathrm{rGO}$ on $\mathrm{H}_{2} \mathrm{Q}$ oxidation. The corresponding $k_{\mathrm{obs}}$ are $9.41 \times 10^{-2} \mathrm{~h}^{-1}$ for $\mathrm{H}_{2} \mathrm{Q}$ and $10.2 \times 10^{-2} \mathrm{~h}^{-1}$ for $\mathrm{BQ}$ (Table 1). BQ is identified as the only oxidation product in the reaction system (Fig. S1). The good mass balance (>95.0\%) calculated by summing up $\mathrm{H}_{2} \mathrm{Q}$ and $\mathrm{BQ}$ indicates the negligible occurrence of other reaction products. 



Fig. 1 - Structural characterization of rGO and graphite. (a) XRD pattern of rGO and graphite, (b) Raman spectra of rGO and graphite, (c) XPS C1s spectrum of rGO.

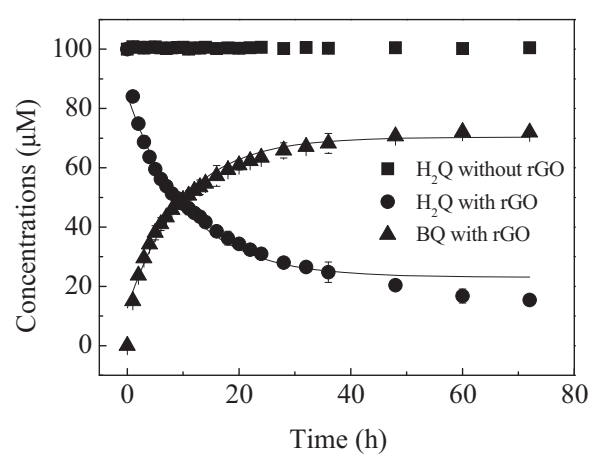

Fig. 2 - Oxidation transformation of $\mathrm{H}_{2} \mathrm{Q}$ to $\mathrm{BQ}$ in the absence and presence of $\mathrm{rGO}$. $(\square) \mathrm{H}_{2} \mathrm{Q}$ in the absence of $\mathrm{rGO}$; $(\Theta) \mathrm{H}_{2} \mathrm{Q}$ in the presence of $\mathrm{rGO}$; (A) produced $\mathrm{BQ}$ mediated by rGO. Reaction conditions: $\left[\mathrm{H}_{2} \mathrm{Q}_{0}=100 \mu \mathrm{M}\right.$, $[\mathrm{rGO}]_{0}=33.3 \mathrm{mg} \mathrm{L}^{-1}, \mathrm{pH}=6.7$. Curve lines for $\mathrm{H}_{2} \mathrm{Q}$ and $\mathrm{BQ}$ in the presence of rGO are modeled by the pseudo-first order kinetic.

To further assess the role of $\mathrm{rGO}$ in promoting $\mathrm{H}_{2} \mathrm{Q}$ transformation, the effect of rGO concentrations is evaluated. As shown in Fig. S3, the transformation of $\mathrm{H}_{2} \mathrm{Q}$ mediated by rGO is acutely sensitive to the concentrations of $\mathrm{rGO}$ in solution. Increasing the $\mathrm{rGO}$ dosage from 0 to $50.0 \mathrm{mg} \mathrm{L}^{-1}$, the concentrations of $\mathrm{H}_{2} \mathrm{Q}$ decreased from initial 100 to $4.8 \mu \mathrm{M}$ after $36 \mathrm{~h}$, and concurrently, the concentrations of $\mathrm{BQ}$ also increases from 0 to $95.9 \mu \mathrm{M}$. There exists a good linear relationship $\left(R^{2}=0.992\right)$ between rGO dosages and the concentrations of $\mathrm{H}_{2} \mathrm{Q} / \mathrm{BQ}$, suggesting the marked mediation ability of $\mathrm{rGO}$ on the oxidation of $\mathrm{H}_{2} \mathrm{Q}$.

\subsection{Effects of solution $p H$}

Since the chemical species of $\mathrm{H}_{2} \mathrm{Q}$ in solution are likely related to its transformation, the oxidation reaction of $\mathrm{H}_{2} \mathrm{Q}$ in the absence and presence of rGO as a function of solution $\mathrm{pH}$ is examined (Fig. S4). In the absence of rGO, it is found that $\mathrm{H}_{2} \mathrm{Q}$ is stable in aqueous solution at $\mathrm{pH}$ 3.0-7.0, but the concentrations of $\mathrm{H}_{2} \mathrm{Q}$ start to decrease at $\mathrm{pH}>7.0$. Considering the $\mathrm{pK}_{\mathrm{a}}$ of $\mathrm{H}_{2} \mathrm{Q}\left(\mathrm{pK}_{\mathrm{a} 1}=10.16\right.$, and $\left.\mathrm{pK}_{\mathrm{a} 2}=12.02\right)$, it is possible that the oxidation reaction of $\mathrm{H}_{2} \mathrm{Q}$ is due to the dissociation of $\mathrm{H}_{2} \mathrm{Q}$ [27]. According to Yuan et al. [28], the autoxidation of $\mathrm{H}_{2} \mathrm{Q}$ is spin-restricted and extremely slow at acidic and neutral $\mathrm{pH}$, but this process can be significantly accelerated when the phenolic $\mathrm{OH}$ groups ionize, which overcomes the spin restriction. At $\mathrm{pH}<7.0, \mathrm{H}_{2} \mathrm{Q}$ mainly exists in the undissociated form $\left(\mathrm{H}_{2} \mathrm{Q}^{0}\right)$. With an increase of solution $\mathrm{pH}$ above

\section{Table 1 - Fitting parameters for $\mathrm{H}_{2} \mathrm{Q}$ and BQ by pseudo-first-order model in the presence of rGO.}

\begin{tabular}{llll} 
Compounds & Fitting equations & $k_{\text {obs }}\left(h^{-1}\right)$ & $R^{2}$ \\
\hline $\mathrm{H}_{2} \mathrm{Q}$ & $y=23.07+61.60 \times \mathrm{e}^{-0.09413 \mathrm{t}}$ & $9.41 \times 10^{-2}$ & 0.97 \\
$\mathrm{BQ}$ & $\mathrm{y}=70.34-57.61 \times \mathrm{e}^{-0.1021 \mathrm{t}}$ & $10.2 \times 10^{-2}$ & 0.99 \\
\hline
\end{tabular}


$\mathrm{pH}$ 7.0, the monodissociated ( $\mathrm{HQ}^{-}$) and/or doubly dissociated $\left(\mathrm{Q}^{2-}\right)$ anions will appear in succession, which are more readily oxidized than $\mathrm{H}_{2} \mathrm{Q}^{0}$ [28].

When rGO is added to the aqueous solution, it is seen that the oxidation reaction of $\mathrm{H}_{2} \mathrm{Q}$ is accelerated at $\mathrm{pH}<9.0$. For example, approximately $31.1-47.4 \% \mathrm{H}_{2} \mathrm{Q}$ is oxidized over the $\mathrm{pH}$ range of 3.0-7.0 within $12 \mathrm{~h}$. An increase of solution $\mathrm{pH}$ from 3.0 to 7.0 causes the oxidation efficiency of $\mathrm{H}_{2} \mathrm{Q}$ slow increase. When solution $\mathrm{pH}$ is increased further, the concentrations of $\mathrm{H}_{2} \mathrm{Q}$ have an abrupt decrease and two curves tend to be close. In alkaline $\mathrm{pH}$ range, the decreased mediation efficiency of rGO can be attributed to the presence of monodissociated $\mathrm{HQ}^{-}$and/or doubly dissociated $\mathrm{Q}^{2-}$. As described above, they have higher activity than $\mathrm{H}_{2} \mathrm{Q}^{0}$, thus their autoxidation are rapid and become the main reaction process in high $\mathrm{pH}$ range.

\subsection{Mechanisms of the mediation effect of rGO}

3.4.1. Mediation effects of different carbonaceous materials The comparison of mediation efficiencies among different carbonaceous materials under aerobic conditions are displayed in Fig. 3. As described above, $\mathrm{H}_{2} \mathrm{Q}$ is stable in aqueous solution, and little autoxidation is observed in the control experiment (in the absence of any carbonaceous materials). When different carbonaceous materials are added at equal mass dose, it is found from Fig. 3 that rGO exhibited stronger mediation efficiency than GO and graphite. For example, about $76.0 \%$ of $\mathrm{H}_{2} \mathrm{Q}$ is transformed to $\mathrm{BQ}$ in the presence of rGO, in comparison with $8.2 \%$ for GO and $3.0 \%$ for graphite. Compared to GO, the significant mediation efficiency of rGO can be ascribed to its high electron transfer capacity based on the literature $[15,16]$. It is well known that graphene basal plane is $2 \mathrm{D}$ crystal lattice with $\mathrm{sp}^{2}$ carbon atoms, which makes each carbon atom have a $\pi$ orbital that contributes to a delocalized network of electrons [29-33]. Undoubtedly, rGO is a good electron conductor. The electric conductivity of rGO is proportional to its $\mathrm{C}: \mathrm{O}$ ratio, i. e., the lower $\mathrm{C}: \mathrm{O}$ ratio means the weaker electron transfer ability [30]. When rGO is oxidized, it is shown that the mediation efficiency of GO decreases significantly with the increase of $\mathrm{O}$ content

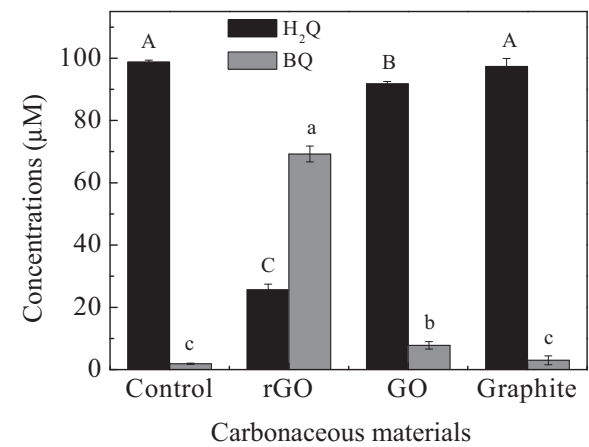

Fig. 3 - Mediation effects of different carbonaceous materials on the oxidation of $\mathrm{H}_{2} \mathrm{Q}$ in aqueous solution. Reaction conditions: $\left[\mathrm{H}_{2} \mathrm{Q}_{0}=100 \mu \mathrm{M}, \mathrm{t}=36 \mathrm{~h}\right.$. Initial concentrations of all carbonaceous materials are $33.3 \mathrm{mg} \mathrm{L}^{-1}$. The error bar (some of which are too small to be visible) represents the standard deviations $(n=3)$.
(Fig. 3), suggesting that the oxidation reaction of $\mathrm{H}_{2} \mathrm{Q}$ is closely related to the electric conductivity of rGO. In fact, enhancement of electron transfer by graphene surfaces has been proposed to explain the mediation effects of graphite, soot, carbon nanotubes, and active carbon on the degradation reactions of nitroaromatic compounds and phenolics $[14,16,17,34-36]$.

Though graphite is also a good electric conductor, its specific surface area is very small $\left(5.0 \mathrm{~m}^{2} \mathrm{~g}^{-1}\right.$ for graphite and $300 \mathrm{~m}^{2} \mathrm{~g}^{-1}$ for $\mathrm{rGO}$ ), which is unfavorable for the contact of $\mathrm{H}_{2} \mathrm{Q}$ with graphite surface and inhibits the oxidation of $\mathrm{H}_{2} \mathrm{Q}$ (Fig. 3). In addition, it is found that, even in equal area dose rGO still has higher mediation efficiency than graphite (Fig. 4). This suggests that some active sites on rGO should be responsible for the enhanced mediation effect of rGO. In comparison with graphite, rGO contains many graphenic edges and defects during its preparation process. These sites are reported to be high reaction activity and can react with dissolved oxygen to produce reactive oxygen species by electron transfer from rGO $[18,19]$. It is significant that these reactive oxygen species are able to react with the coexisting $\mathrm{H}_{2} \mathrm{Q}$ and facilitate the oxidation reaction of $\mathrm{H}_{2} \mathrm{Q}$.

\subsubsection{Role of dissolved oxygen}

To gain some insight into the rapid oxidation of $\mathrm{H}_{2} \mathrm{Q}$ in $\mathrm{rGO}$ system at neutral $\mathrm{pH}$, the role of dissolved oxygen and the intermediate and terminal products are investigated. As shown in Fig. 5, we examine the effects of dissolved oxygen on the oxidation of $\mathrm{H}_{2} \mathrm{Q}$ in the presence of rGO. Consistent with our above results, it is found that $\mathrm{H}_{2} \mathrm{Q}$ in $\mathrm{rGO}$ suspended solution is transformed to $\mathrm{BQ}$ rapidly in the presence of dissolved oxygen, and about $78.9 \% \mathrm{H}_{2} \mathrm{Q}$ is removed within $36 \mathrm{~h}$. If dissolved oxygen is excluded, interestingly, it is found that the oxidation reaction of $\mathrm{H}_{2} \mathrm{Q}$ ceases and $\mathrm{H}_{2} \mathrm{Q}$ is stable within the whole time range. This result suggests that dissolved oxygen takes part in the reaction process and plays a vital role in the transformation of $\mathrm{H}_{2} \mathrm{Q}$ to $\mathrm{BQ}$.

The reaction of dissolved oxygen with carbon surface had been widely studied [18-20], where dissolved oxygen reacts with active sites on graphenic carbon surface to produce surface-bound oxygen intermediates, such as adsorbed

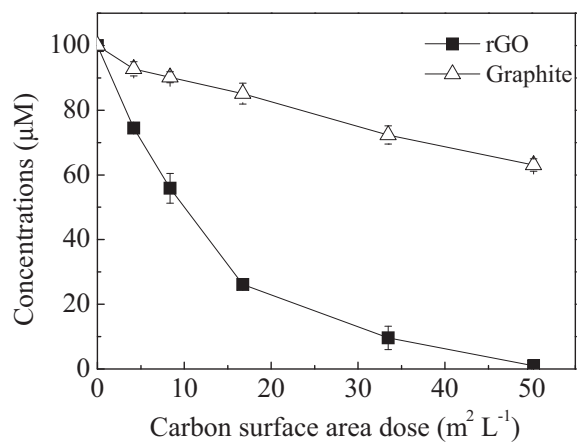

Fig. 4 - Mediation effects of rGo $(\square)$ and graphite $(\triangle)$ on the oxidation of $\mathrm{H}_{2} \mathrm{Q}$ as a function of surface area dose. Reaction conditions: $\left[\mathrm{H}_{2} \mathrm{Q}\right]_{0}=100 \mu \mathrm{M}, t=36 \mathrm{~h}$. The error bar (some of which are too small to be visible) represents the standard deviations $(n=3)$. 


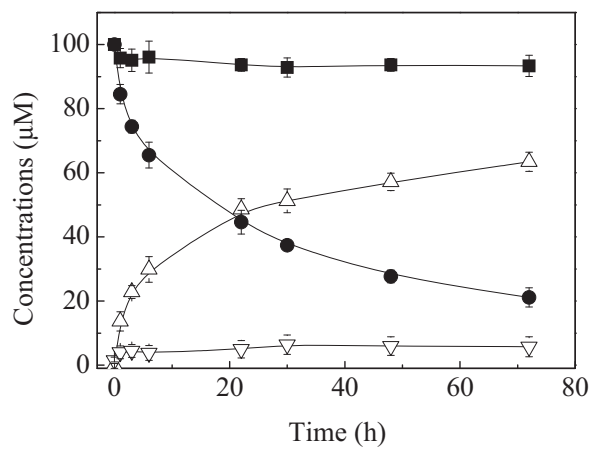

Fig. 5 - Effects of dissolved oxygen on the oxidation of $\mathrm{H}_{2} \mathrm{Q}$ in the presence of rGO. ( $\square$ ) $\mathrm{H}_{2} \mathrm{Q}$ in the absence of dissolved oxygen; (Ө) $\mathrm{H}_{2} \mathrm{Q}$ in the presence of dissolved oxygen; $(\triangle)$ produced BQ in the presence of dissolved oxygen; $(\nabla)$ produced $B Q$ in the absence of dissolved oxygen. Reaction conditions: $\left[\mathrm{H}_{2} \mathrm{Q}_{0}=100 \mu \mathrm{M},[\mathrm{rGO}]_{0}=33.3 \mathrm{mg} \mathrm{L}^{-1}, \mathrm{pH}=6.7\right.$. The error bar (some of which are too small to be visible) represents the standard deviations $(n=3)$.

superoxide anion $\mathrm{C}_{\mathrm{s}}\left(\mathrm{O}_{2}^{-}\right)$, or hydroperoxide $\mathrm{C}_{\mathrm{s}}(\mathrm{OOH})[18,19]$. In this study, these generated surface-bound oxygen intermediates are thought to capture $\mathrm{H}$ atoms from $\mathrm{H}_{2} \mathrm{Q}$ molecular and facilitate the generation of semiquinone radical (SQ- $)$. Using the EPR technique, we determine the signal intensity of $\mathrm{SQ}^{-}$in solution. As shown in Fig. 6, the signal intensity of $\mathrm{SQ}^{-}$is weak at $\mathrm{pH} 6.7$ under aerobic environment in the absence of rGO. When $\mathrm{rGO}$ is introduced into the reaction system, it is found that the signal intensity of $\mathrm{SQ}^{-}$has a pronounced increase, suggesting that rGO stimulates the generation of $\mathrm{SQ}^{-}$. If the dissolved oxygen in rGO system is partially removed, as seen in Fig. 6c, the signal intensity of $\mathrm{SQ}^{-}$is significantly inhibited under anaerobic condition. The above results imply that rGO and dissolved oxygen are two key factors to produce $\mathrm{SQ}^{-}$.

However, the formation of $\mathrm{SQ}^{--}$is only the first stage of the oxidation reaction of $\mathrm{H}_{2} \mathrm{Q}$. The radical continues to transfer an electron to molecular oxygen to generate superoxide radical $\left(\mathrm{O}_{2}^{-}\right)$and $\mathrm{BQ}$ (reaction (2)) $[37,38]$. Repeated attempt has been made to detect the appearance of $\mathrm{O}_{2}^{--}$. Unfortunately,

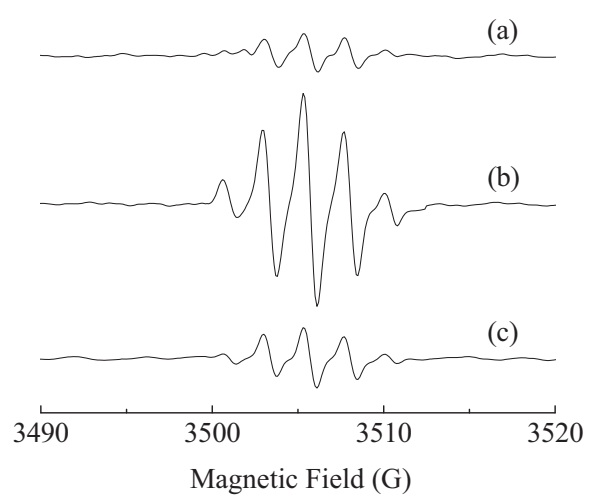

Fig. 6 - EPR spectra of the generated SQ:- from $\mathrm{H}_{2} \mathrm{Q}$, (a) in the absence of rGO under aerobic condition; (b) in the presence of rGO under aerobic condition; (c) in the presence of rGO under anaerobic condition.
$\mathrm{O}_{2}^{--}$is very short-lived, and the production of $\mathrm{O}_{2}^{--}$could not be observed using 5,5-dimethyl-1-pyrroline $\mathrm{N}$-oxide as a spin trapping agent due to the possible rapid reaction of $\mathrm{O}_{2}^{--}$with $\mathrm{H}^{+}$and/or $\mathrm{H}_{2} \mathrm{Q}$ (reactions (3) and (4)) or scavenging by carbon surface [39]. Finally, we determine the possible occurrence of hydrogen peroxide in the reaction solution. Result shows that as $\mathrm{H}_{2} \mathrm{Q}$ is oxidized to $\mathrm{BQ}$, the concomitant hydrogen peroxide is formed at the same time (Fig. S5) [40-42]. This result is consistent with the observation of Eyer [43], and indicates the chain-propagating role of $\mathrm{O}_{2}^{--}$in the oxidation reaction of $\mathrm{H}_{2} \mathrm{Q}$ to some extent:

$\mathrm{SQ}^{--}+\mathrm{O}_{2} \rightleftharpoons \mathrm{O}_{2}^{--}+\mathrm{BQ}$

$2 \mathrm{O}_{2}^{--}+2 \mathrm{H}^{+} \rightleftharpoons \mathrm{O}_{2}+\mathrm{H}_{2} \mathrm{O}_{2}$

$\mathrm{H}_{2} \mathrm{Q}+\mathrm{O}_{2}^{--} \rightleftharpoons \mathrm{SQ}^{--}+\mathrm{H}_{2} \mathrm{O}_{2}$

These observations above demonstrate that dissolved oxygen will be consumed in the oxidation reaction of $\mathrm{H}_{2} \mathrm{Q}$ giving rise to the formation of $\mathrm{BQ}$ and hydrogen peroxide, the net reaction being

$\mathrm{H}_{2} \mathrm{Q}+\mathrm{O}_{2} \stackrel{\mathrm{rGO}}{\rightarrow} \mathrm{BQ}+\mathrm{H}_{2} \mathrm{O}_{2}$

In addition, we also examine the possible interference of metal impurities in $\mathrm{rGO}$ on the oxidation reaction of $\mathrm{H}_{2} \mathrm{Q}$ [21]. rGO is washed with $3 \mathrm{M} \mathrm{HCl}$ followed by hot water wash as described in Liu et al. [44]. The final result demonstrates that there is no significant difference between the mediation efficiencies of treated and untreated rGO (data not shown). The result suggests that the accelerated oxidation reaction of $\mathrm{H}_{2} \mathrm{Q}$ is not due to the metal impurities in rGO.

\section{Conclusion}

The present study demonstrated a novel role of $\mathrm{rGO}$ as redox mediator in accelerating the oxidative transformation of $\mathrm{H}_{2} \mathrm{Q}$ to $\mathrm{BQ}$ at $\mathrm{pH}$ 6.7. It is found that the presence of $\mathrm{rGO}$ markedly increases the oxidation rate of $\mathrm{H}_{2} \mathrm{Q}$ under ambient aerobic condition. The enhancement effects of rGO are attributed to the combined contribution of the graphenic edges and defects on rGO and the high electron conductivity of rGO. The graphenic edges and defects on $\mathrm{rGO}$ can react with dissolved oxygen to form surface-bound oxygen intermediates by electron transfer. Subsequently, these surface-bound oxygen intermediates capture $\mathrm{H}$ atoms from the phenolic hydroxyl groups of $\mathrm{H}_{2} \mathrm{Q}$ and stimulate the generation of $\mathrm{SQ}^{-}$. The generated $\mathrm{SQ}^{-}$transfers an electron to dissolved oxygen to yield $\mathrm{O}_{2}^{--}$ and $\mathrm{BQ}$. Then $\mathrm{O}_{2}^{-}$continues to react with $\mathrm{H}_{2} \mathrm{Q}$ or $\mathrm{H}^{+}$to produce $\mathrm{SQ}^{-}$and $\mathrm{H}_{2} \mathrm{O}_{2}$. This finding highlights that $\mathrm{rGO}$ can not only act as superb adsorbents for organic contaminants but also function as efficient mediators to accelerate the redox reaction of coexisting chemicals. Relevant knowledge provides new information for the risk assessment of both rGO and other coexisting phenolic contaminants in aqueous environment.

\section{Acknowledgments}

This work was funded by National Key Basic Research Program of China (973 Program) (2014CB441102), National 
Natural Science Foundation of China (Grant Numbers: 21477145, 21277159, 21103080 and 21321004), and the Strategic Priority Research Program of the Chinese Academy of Sciences (Grant Number: XDB14020202).

\section{Appendix A. Supplementary data}

Supplementary data associated with this article can be found, in the online version, at http://dx.doi.org/10.1016/j.carbon. 2015.03.027.

\section{R E F E R E N C E S}

[1] Geim AK, Novoselov KS. The rise of graphene. Nat Mater 2007;6:183-91.

[2] Novoselov KS, Geim AK, Morozov S, Jiang D, Zhang Y, Dubonos S, et al. Electric field effect in atomically thin carbon films. Science 2004;306:666-9.

[3] Pei ZG, Li LY, Sun LY, Zhang SZ, Shan XQ, Yang S, et al. Adsorption characteristics of 1,2,4-trichlorobenzene, 2,4,6trichlorophenol, 2-naphthol and naphthalene on graphene and graphene oxide. Carbon 2013;51:156-63.

[4] Zhao GX, Jiang L, He YD, Li JX, Dong HL, Wang XK, et al. Sulfonated graphene for persistent aromatic pollutant management. Adv Mater 2011;23:3959-63.

[5] Wang F, Haftka JJH, Sinnige TL, Hermens JLM, Chen W. Adsorption of polar, nonpolar, and substituted aromatics to colloidal graphene oxide nanoparticles. Environ Pollut 2014;186:226-33.

[6] Wang J, Chen ZM, Chen BL. Adsorption of polycyclic aromatic hydrocarbons by graphene and graphene oxide nanosheets. Environ Sci Technol 2014;48:4817-25.

[7] Sun L, Yu HW, Fugetsu B. Graphene oxide adsorption enhanced by in situ reduction with sodium hydrosulfite to remove acridine orange from aqueous solution. J Hazard Mater 2012;203:101-10.

[8] Gao Y, Li Y, Zhang L, Huang H, Hu JJ, Shah SM, et al. Adsorption and removal of tetracycline antibiotics from aqueous solution by graphene oxide. J Colloid Interface Sci 2012;368:540-6.

[9] Maliyekkal SM, Sreeprasad TS, Krishnan D, Kouser S, Mishra AK, Waghmare UV, et al. Graphene: a reusable substrate for unprecedented adsorption of pesticides. Small 2013;9:273-83.

[10] Zhao G, Li JX, Ren XM, Chen CL, Wang XK. Few-layered graphene oxide nanosheets as superior sorbents for heavy metal ion pollution management. Environ Sci Technol 2011;45:10454-62.

[11] Yang S, Li LY, Pei ZG, Li CM, Shan XQ, Wen B. Effects of humic acid on copper adsorption onto graphene and graphene oxide. Carbon 2014;75:227-35.

[12] Wang XB, Huang SS, Zhu LH, Tian XL, Li SH, Tang HQ. Correlation between the adsorption ability and reduction degree of graphene oxide and tuning of adsorption of phenolic compounds. Carbon 2014;69:101-12.

[13] Fu HY, Zhu DQ. Graphene oxide-facilitated reduction of nitrobenzene in sulfide-containing aqueous solutions. Environ Sci Technol 2013;47:4204-10.

[14] Fu HY, Guo Y, Chen W, Gu C, Zhu DQ. Reductive dechlorination of hexachloroethane by sulfide in aqueous solutions mediated by graphene oxide and carbon nanotubes. Carbon 2014;72:74-81.

[15] Sun HQ Liu SZ, Zhou GL, Ang HM, Tadé MO, Wang SB. Reduced graphene oxide for catalytic oxidation of aqueous organic pollutants. ACS Appl Mater Interfaces 2012;4:5466-71.
[16] Lightcap IV, Kosel TH, Kamat PV. Anchoring semiconductor and metal nanoparticles on a two-dimensional catalyst mat. Storing and shuttling electrons with reduced graphene oxide. Nano Lett 2010;10:577-83.

[17] Luo J, Peng F, Yu H, Wang HJ. Selective liquid phase oxidation of benzyl alcohol catalyzed by carbon nanotubes. Chem Eng J 2012;204:98-106.

[18] Liu XY, Sen SJ, Liu JY, Kulaots I, Geohegan D, Kane A, et al. Antioxidant deactivation on graphenic nanocarbon surfaces. Small 2011;7:2775-85.

[19] Qu DY. Investigation of oxygen reduction on activated carbon electrodes in alkaline solution. Carbon 2007;45:1296-301.

[20] Liang J, Jiao Y, Jaroniec M, Qiao SZ. Sulfur and nitrogen dualdoped mesoporous graphene electrocatalyst for oxygen reduction with synergistically enhanced performance. Angew Chem Int Ed 2012;51:11496-500.

[21] Wang L, Ambrosi A, Pumera M. "Metal-free" catalytic oxygen reduction reaction on heteroatom-doped graphene is caused by trace metal impurities. Angew Chem Int Ed 2013;52:13818-21.

[22] Zhang LW, Petersen EJ, Huang QG. Phase distribution of ${ }^{14} \mathrm{C}$ labeled multiwalled carbon nanotubes in aqueous systems containing model solids: peat. Environ Sci Technol 2011;45:1356-62.

[23] Chen CM, Yang QH, Yang YG, Lv W, Wen YF, Hou PX, et al. Self-assembled free-standing graphite oxide membrane. Adv Mater 2009;21:3007-11.

[24] Chen CM, Zhang Q, Yang MG, Huang CH, Yang YG, Wang MZ. Structural evolution during annealing of thermally reduced graphene nanosheets for application in supercapacitors. Carbon 2012;50:3572-84.

[25] Zhou M, Diwu Z, Panchuk-Voloshina N, Haugland RP. A stable nonfluorescent derivative of resorufin for the fluorometric determination of trace hydrogen peroxide: applications in detecting the activity of phagocyte NADPH oxidase and other oxidases. Anal Biochem 1997;253:162-8.

[26] Guo F, Creighton M, Chen YT, Hurt R, Külaots I. Porous structures in stacked, crumpled and pillared graphene-based 3D materials. Carbon 2014;66:476-84.

[27] Pedersen JA. Electron-spin resonance studies of oxidative process of quinones and hydroquinones in alkaline solution; formation of primary and secondary semiquinone radicals. J Chem Soc Perkin Trans 2 $1973 ; 2: 424-31$.

[28] Yuan X, Pham AN, Miller CJ, Waite TD. Copper-catalyzed hydroquinone oxidation and associated redox cycling of copper under conditions typical of natural saline waters. Environ Sci Technol 2013;47:8355-64.

[29] Stankovich S, Dikin DA, Piner RD, Kohlhaas KA, Kleinhammes A, Jia Y, et al. Synthesis of graphene-based nanosheets via chemical reduction of exfoliated graphite oxide. Carbon 2007;45:1558-65.

[30] Shin HJ, Kim KK, Benayad A, Yoon SM, Park HK, Jung IS, et al. Efficient reduction of graphite oxide by sodium borohydride and its effect on electrical conductance. Adv Funct Mater 2009;19:1987-92.

[31] Che J, Shen L, Xiao Y. A new approach to fabricate graphene nanosheets in organic medium: combination of reduction and dispersion. J Mater Chem 2010;20:1722-7.

[32] Dreyer DR, Park S, Bielawski CW, Ruoff RS. The chemistry of graphene oxide. Chem Soc Rev 2010;39:228-40.

[33] Zhu Y, Murali S, Cai W, Li X, Suk JW, Potts JR, et al. Graphene and graphene oxide: synthesis, properties, and applications. Adv Mater 2010;22:3906-24.

[34] Van Der Zee FP, Bisschops IA, Lettinga G, Field JA. Activated carbon as an electron acceptor and redox mediator during the anaerobic biotransformation of azo dyes. Environ Sci Technol 2003;37:402-8. 
[35] Oh SY, Chiu PC. Graphite- and soot-mediated reduction of 2,4-dinitrotoluene and hexahydro-1,3,5-trinitro-1,3,5triazine. Environ Sci Technol 2009;43:6983-8.

[36] Padhye L, Wang P, Karanfil T, Huang CH. Unexpected role of activated carbon in promoting transformation of secondary amines to N-nitrosamines. Environ Sci Technol 2010;44:4161-8.

[37] Geng QJ, Guo QJ, Cao CQ Wang LT. Investigation into nano $\mathrm{TiO}_{2} /$ ACSPCR for decomposition of aqueous hydroquinone. Ind Eng Chem Res 2008;47:2561-8.

[38] Roginsky V, Alegria AE. Oxidation of tea extracts and tea catechins by molecular oxygen. J Agric Food Chem 2005;53:4529-35.

[39] Qiu Y, Wang ZY, Owens ACE, Kulaots I, Chen YT, Kane AB. Antioxidant chemistry of graphene-based materials and its role in oxidation protection technology. Nanoscale 2014;6:11744-55.
[40] Song Y, Wagner BA, Lehmler HJ, Buettner GR. Semiquinone radicals from oxygenated polychlorinated biphenyls:

electron paramagnetic resonance studies. Chem Res Toxicol 2008;21:1359-67.

[41] Roginsky V, Barsukova T. Kinetics of oxidation of hydroquinones by molecular oxygen. Effect of superoxide dismutase. J Chem Soc Perkin Trans 2 2000:1575-82.

[42] Song Y, Buettner GR. Thermodynamic and kinetic considerations for the reaction of semiquinone radicals to form superoxide and hydrogen peroxide. Free Radical Biol Med 2010;49:919-62.

[43] Eyer P. Effects of superoxide-dismutase on the autoxidation of 1,4-hydroquinone. Chem Biol Interact 1991;80:159-76.

[44] Liu XY, Guo L, Morris D, Kane AB, Hurt RH. Targeted removal of bioavailable metal as a detoxification strategy for carbon nanotubes. Carbon 2008;46:489-500. 